\title{
Single-port laparoscopic colectomy versus conventional laparoscopic colectomy for colon cancer: a comparison of surgical results
}

\author{
Hiroyuki Egi ${ }^{1,2^{*}}$, Minoru Hattori ${ }^{2}$, Takao Hinoi ${ }^{1}$, Yuji Takakura ${ }^{1}$, Yasuo Kawaguchi ${ }^{1}$, Manabu Shimomura', \\ Masakazu Tokunaga ${ }^{1}$, Tomohiro Adachi ${ }^{1}$, Takashi Urushihara ${ }^{3}$, Toshiyuki Itamoto ${ }^{3}$ and Hideki Ohdan ${ }^{1}$
}

\begin{abstract}
Background: Single-port laparoscopic surgery is a new technique that leaves no visible scar. This new technique has generated strong interest among surgeons worldwide. However, single-port laparoscopic colon surgery has not yet been standardized. Our aim in this study was to evaluate the feasibility of single-port laparoscopic colectomy compared with conventional laparoscopic colectomy for colon cancer.

Methods: We conducted a case-matched, controlled study comparing single-port laparoscopic colectomy to conventional laparoscopic colectomy for right-sided colon cancer.

Results: A total of ten patients were included for the single-port laparoscopic colectomy (S-LAC) group and ten patients for the conventional laparoscopic colectomy (C-LAC) group. The length of the skin incision in the S-LAC group was significantly shorter than that of the C-LAC group.

Conclusion: Our early experiences indicated that S-LAC for right-sided colon cancer is a feasible and safe procedure and that S-LAC results in a better cosmetic outcome.

Keywords: Single-port laparoscopic surgery, Single-incision laparoscopic surgery, Conventional laparoscopic surgery, Laparoscopic colectomy, Colon cancer, Gelport
\end{abstract}

\section{Background}

Laparoscopic surgery has been a standard strategy for a variety of gastrointestinal diseases. The first report about laparoscopic colectomy was published by Jacobs et al. [1] two decades ago. Since then the use of laparoscopic colectomy for colon cancer has gradually increased, and it is now acceptable treatment not only for early colon cancer but also for advanced cases because of its oncological safety and feasibility $[2,3]$. Recently, natural orifice transluminal endoscopic surgery (NOTES) has been studied as the next generation of minimally invasive surgery. This new technique was described for the first time by Kalloo et al., who introduced their work performing transgastric peritoneoscopy in a porcine model [4]. Marescaux et al.

\footnotetext{
* Correspondence: hiroegi@yahoo.co.jp

'Department of Surgery, Division of Frontier Medical Science, Programs for Biomedical Research, Graduate School of Biomedical Sciences, Hiroshima

University, 1-2-3 Kasumi, Minami-ku, Hiroshima 734-8551, Japan

Full list of author information is available at the end of the article
}

also reported successful NOTES in a clinical case [5]. However, the feasibility and safety of NOTES have not been evaluated. Single-port laparoscopic surgery is also a new technique which leaves no visible scar. This new technique has generated interest among surgeons worldwide. Although the use of single-port laparoscopic cholecystectomy has spread rapidly, single-incision laparoscopic colon surgery has not yet been standardized. Our aim in this study was to evaluate the feasibility of single-port laparoscopic colectomy compared with conventional laparoscopic colectomy for colon cancer which requires D2 lymph node dissection.

\section{Methods}

This study was performed with permission of the Ethics Committee of the Hiroshima University.

We conducted a case-matched, controlled study comparing single-port laparoscopic colectomy to conventional laparoscopic colectomy for right-sided colon

\section{C) Biomed Central}


cancer. The inclusion criteria were right-sided colon cancer which required colon resection with D2 lymph node dissection. The single-port laparoscopic colectomy group included selected patients who completed their treatment between February 2010 and March $2011(n=10)$. Patients who underwent conventional laparoscopic surgery for right-sided colon cancer between April 2006 and March 2010 were selected as the control group for this study $(n=10)$. These patients were matched with regard to the patient's age, sex, body mass index (BMI), American Society of Anesthesiologists (ASA) score, history of abdominal surgery, disease type and tumor location. No consideration or analysis of surgical parameters and outcomes was made until these groups were definitively selected as the best comparison cohort based only on preoperative variables.

\section{Surgical technique}

After obtaining informed consent, we placed patients with right-sided colon cancer in the supine position. The surgical methods for both single-port laparoscopic colectomy (S-LAC) and conventional laparoscopic colectomy (C-LAC) were performed using a mediolateral approach, and the hand-sewn anastomoses were performed extracorporeally. In the S-LAC group, a 3-cm skin incision was made in the umbilicus and laparotomy was performed. The Gelport (Applied Medical, Rancho Santa Margarita, CA, USA) was inserted through this incision and used as the access port. We usually used three trocars of different sizes (Ethicon, Inc, Cincinnati, $\mathrm{OH}, \mathrm{USA}$ ) to prevent clashes between these trocars. The camera was a flexible videolaparoscope (Olympus Medical Systems Corp, Tokyo, Japan), and the energy source was the Harmonic Ace (Ethicon, Inc). The other laparoscopic instruments were the same as those used in conventional laparoscopic colonic surgery (Figure 1). For the C-LAC group, the first trocar was inserted through the infraumbilical incision, and another four trocars were inserted sequentially. After intracorporeal completion of the procedure, a small skin incision was made in the lower abdomen or umbilicus. All instruments used, including the camera and energy device, were the same in both the C-LAC and S-LAC groups.

The perioperative outcomes, including the surgical method, length of skin incision, length of operation, estimated blood loss and conversion rate to conventional laparoscopic surgery or open surgery, as well as the complications, were analyzed (Table 1). The pathological findings included the degree of differentiation, depth, presence of lymph node metastasis, lymphatic vessel invasion, vascular invasion and the number of lymph nodes resected, and these results were analyzed as well (Table 2).

\section{Statistical analysis}

All continuous variables are expressed as the median (range) and were compared using the Mann-Whitney $U$ test. The $\chi^{2}$ test and Fisher's exact test were used to compare discrete variables. Statistical calculations were performed with the help of the SPSS version 18.0 software program (SPSS, Chicago, IL, USA), and a $P$ value $<0.05$ was considered to indicate statistical significance.

\section{Results}

Twenty patients ( 8 males and 12 females) were enrolled in this study, and they were distributed into two groups: S-LAC and C-LAC. All patients were matched as closely as possible in terms of their selection criteria. The data for both groups are shown in Table 3. There was no surgical mortality or reintervention within 30 days in either group. There were no significant differences in the lengths of the operations between the S-LAC group (median 192 minutes, range 156 to $231 \mathrm{~min}$ ) and the CLAC group (median 222 minutes, range 44 to 244 minutes). There also were no significant differences in the estimated blood loss between the S-LAC group (median
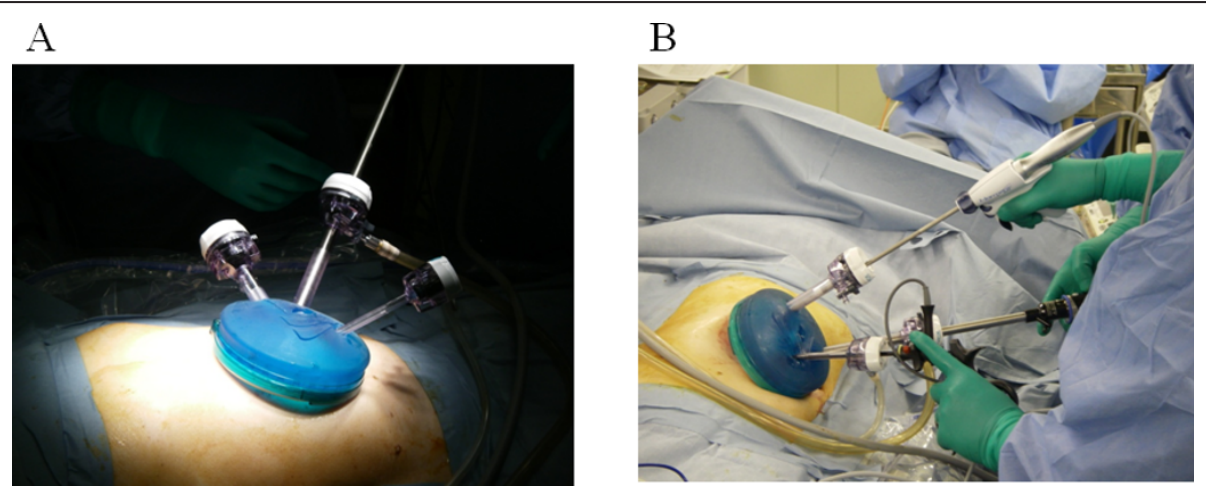

Figure 1 The Gelport was used as the access port. The flexible videolaparoscope, the Harmonic Ace energy source and other laparoscopic instruments used were the same as those used in the conventional laparoscopic colectomy group. 
Table 1 Perioperative outcomes ${ }^{\mathrm{a}}$

\begin{tabular}{|c|c|c|c|}
\hline \multirow[b]{2}{*}{ Parameters } & \multicolumn{3}{|c|}{ Laparoscopic colectomy for colon cancer } \\
\hline & S-LAC $(N=10)$ & C-LAC $(N=10)$ & $P$ value \\
\hline Method & & & 0.141 \\
\hline Ileocecal resection & 8 & 5 & \\
\hline Right hemicolectomy & 1 & 5 & \\
\hline Transverse colectomy & 1 & 0 & \\
\hline Operative time (minutes) & $192.0(156$ to 231$)$ & 222.0 (44 to 244$)$ & 0.063 \\
\hline Estimated blood loss (ml) & $48.0(0$ to 110$)$ & 51.5 (21 to 244$)$ & 0.190 \\
\hline Length of skin incision $(\mathrm{cm})$ & 3 (2 to 3 ) & 5 (3 to 6) & $<0.001$ \\
\hline Conversion rate (\%) & $0(0 \%)$ & $1(10.0 \%)$ & 0.474 \\
\hline Hospital stay after operation (days) & $8.0(6$ to 13$)$ & 10.5 (7 to 21$)$ & 0.023 \\
\hline
\end{tabular}

${ }^{a} \mathrm{C}-\mathrm{LAC}=$ conventional laparoscopic colectomy; S-LAC $=$ single-port laparoscopic colectomy. Data are expressed as median (range) or as raw numbers.

$48.0 \mathrm{ml}$, range 0 to $110 \mathrm{ml}$ ) and the C-LAC group (median $51.5 \mathrm{ml}$, range 21 to $244 \mathrm{ml}$ ). Although there was one conversion to open surgery in the C-LAC group due to anatomical difficulties, there were no conversions in the S-LAC group. Regarding the length of the skin incision, that in the S-LAC group (median $3.0 \mathrm{~cm}$, range 2.0 to $3.0 \mathrm{~cm}$ ) was significantly shorter than that of the C-LAC group (median $5.0 \mathrm{~cm}$, range 3.0 to $6.0 \mathrm{~cm} ; P<$ 0.001). In terms of the hospital stay, the median stay of 8.0 days in the S-LAC group (range 6 to 13 days) was significantly shorter than the median of 10.5 days in the C-LAC group (range, 7 to 21 days; $P=0.023$ ), as shown in Table 1. There were no surgical complications, including anastomotic leakage, surgical site infection, ileus, pneumonia, liver and renal dysfunction, or cardiovascular disease in either group (data not shown). With regard to the pathological findings, including the tumor differentiation, depth of the tumor, node metastasis, lymphatic invasion and vascular invasion, there were no significant differences between the groups. Moreover,

Table 2 Pathological outcomes ${ }^{a}$

\begin{tabular}{|c|c|c|c|}
\hline \multirow[b]{2}{*}{ Parameters } & \multicolumn{3}{|c|}{ Laparoscopic colectomy for colon cancer } \\
\hline & S-LAC $(N=10)$ & C-LAC $(N=10)$ & $P$ value \\
\hline Differentiation & & & 0.661 \\
\hline Well & 7 & 6 & \\
\hline Moderate & 1 & 2 & \\
\hline Pap & 1 & 0 & \\
\hline Well-differentiated endocrine carcinoma & 0 & 1 & \\
\hline Adenoma & 1 & 1 & \\
\hline Depth & & & 0.459 \\
\hline m (membrane) & 4 & 3 & \\
\hline sm (lymphatic invasion) & 6 & 4 & \\
\hline mp (vascular invasion) & 0 & 1 & \\
\hline a & 0 & 2 & \\
\hline$n$ & & & 1.000 \\
\hline Negative & 10 & 9 & \\
\hline Positive & 0 & 1 & \\
\hline ly & & & 0.211 \\
\hline Negative & 10 & 7 & \\
\hline Positive & 0 & 3 & \\
\hline V & & & 1.000 \\
\hline Negative & 9 & 9 & \\
\hline Positive & 1 & 1 & \\
\hline Lymph node harvest, median (range) & 15.0 (3 to 30$)$ & 16.5 (3 to 23$)$ & 0.853 \\
\hline
\end{tabular}

${ }^{\mathrm{a} C-L A C}=$ conventional laparoscopic colectomy; S-LAC = single-port laparoscopic colectomy. Data are expressed as median (range) or as raw numbers. 
Table 3 Preoperative parameters of patients ${ }^{a}$

\begin{tabular}{|c|c|c|c|}
\hline \multirow[b]{2}{*}{ Demographics } & \multicolumn{3}{|c|}{ Laparoscopic colectomy for colon cancer } \\
\hline & S-LAC & C-LAC & $P$ value \\
\hline Number of Patients & 10 & 10 & \\
\hline Age (years) & $68.5(61$ to 81$)$ & 68.0 (33 to 84$)$ & 0.853 \\
\hline Sex & & & 1.000 \\
\hline Male & 4 & 4 & \\
\hline Female & 6 & 6 & \\
\hline $\mathrm{BMI}\left(\mathrm{kg} / \mathrm{m}^{2}\right)$ & 22.5 (19.6 to 24.6$)$ & 21.9 (17.1 to 26.2$)$ & 0.353 \\
\hline ASA score & & & 1.000 \\
\hline 1 & 8 & 7 & \\
\hline 2 & 2 & 3 & \\
\hline Prior abdominal surgery rate (\%) & $2(20 \%)$ & $3(0 \%)$ & 1.000 \\
\hline Type (Japanese Society for Cancer of the Colon and Rectum, 7th edition) & & & 0.087 \\
\hline 0 & 10 & 6 & \\
\hline 1 & 0 & 3 & \\
\hline 2 & 0 & 1 & \\
\hline Location & & & 0.057 \\
\hline C (Cecum) & 5 & 1 & \\
\hline A (Ascending colon) & 4 & 9 & \\
\hline T (Transverse colon) & 1 & 0 & \\
\hline
\end{tabular}

the median number of lymph nodes extracted was also not significantly different between the S-LAC group (median 15.0, range 3 to 30 ) and the C-LAC group (median 16.5, range 3 to 23), as shown in Table 2.

\section{Discussion}

The use of single-port laparoscopic cholecystectomy has spread rapidly, and many procedures have already been performed throughout the world. On the other hand, single-port laparoscopic colon surgery for colon cancer has not yet been standardized. There are only a few reports of small sample size studies in the literature [6-14]. It has been suggested that single-port laparoscopic colectomy for colon cancer provides a better cosmetic outcome for patients than conventional laparoscopic surgery, with equivalent invasiveness between the procedures. However, there has been no adequate evidence regarding not only these issues but also the feasibility and safety of this operation. In this study, we compared various parameters between S-LAC and C-LAC to evaluate the feasibility and safety, as well as the outcomes, of single-port laparoscopic colectomy for colon cancer which required D2 lymph node dissection.

The apparent advantage of single-port laparoscopic colectomy is a better cosmetic outcome. Our data also reveal that the median length of the skin incision in the SLAC group of $3.0 \mathrm{~cm}$ (range 2.0 to $3.0 \mathrm{~cm}$ ) was significantly shorter than that of $5.0 \mathrm{~cm}$ in the C-LAC group (range 3.0 to $6.0 \mathrm{~cm})(P<0.001)$. To evaluate the invasiveness of the procedure, we compared the length of the operation, estimated blood loss and hospital stay. In our series, there were no significant differences between the SLAC and C-LAC groups regarding the length of the operation or estimated blood loss. In terms of the hospital stay, the median of 8.0 days in the S-LAC group (range 6 to 13 days) was significantly shorter than the median of 10.5 days in the C-LAC group (range 7 to 21 days) $(P=0.023)$. Generally, the duration of the hospital stay has been used as one of the most important parameters of invasiveness. However, the hospital stay is defined not only by the patient's situation but also based on the characteristics of many Japanese patients who hope to stay for a long period in the hospital. Hence, the hospital stay is not necessarily a reliable parameter on which to objectively assess the invasiveness of such patients. However, these findings demonstrate that S-LAC is not more invasive than C-LAC or open colectomy.

The main disadvantage of this procedure is the difficulty in performing it, owing to the lack of instrument triangulation, clashing of the instruments outside the abdomen, a requirement for articulated instruments and the potential for pneumoperitoneum leaks. To resolve these problems, we primarily use the Gelport as the access port. In other words, the most important point for ensuring successful single-port laparoscopic colectomy is the selection of the access port to use. Initially, the multiple fascial puncture 
technique under a skin flap [15] was used for single-incision laparoscopic surgery, especially for cholecystectomy. However, the disadvantages of this technique are the weakness of the fascia due to the creation of multiple defects, as well as seroma formation. Therefore, several new access ports have already been developed. We usually use the Gelport, which has been used for hand-assisted laparoscopic surgery, as the access port for single-port laparoscopic colectomy. The benefit of using the Gelport is that several trocars can be inserted multiple times if necessary, and the trocars can be kept apart for as long as possible to maintain instrument triangulation and to prevent instrument clashing outside the abdomen. The most important issue affecting single-port laparoscopic colectomy is the much smaller space outside the abdomen than is present during conventional laparoscopic surgery. This difficult situation requires the use of articulated instruments. However, we did not need to use any articulated instruments when we used the Gelport as the access port. Moreover, the Gelport was able to maintain an airtight seal during the operation. Therefore, we concluded that our method using the Gelport has the potential to successfully address these limitations [16].

Our series of single-port laparoscopic colectomies for colon cancers $(n=10)$ had no conversions (Table 1$)$ and no surgical complications, including anastomotic leakage, surgical site infection, ileus, pneumonia, cardiovascular disease and so on. These results revealed the feasibility and safety of single-port laparoscopic colectomy for colon cancer during the perioperative period.

In terms of the median number of extracted lymph nodes, there were no significant differences between the SLAC group (median 15.0, range 3 to 30) and the C-LAC group (median 16.5, range 3 to 23$)(P=0.912)$, as shown in Table 2. These results demonstrate the feasibility regarding the short-term oncologic outcomeof single-port laparoscopic colectomy for colon cancer which requires D2 lymph node dissection.

This study is limited by its small sample size. However, it provides an initial comparison between S-LAC and CLAC and can provide the foundation for large, randomized controlled studies.

\section{Conclusion}

Our early experiences indicates that S-LAC for right-sided colon cancer is a feasible and safe procedure. Although there were no significant benefits regarding the perioperative and oncological results, S-LAC does provide a better cosmetic outcome. Before extending the indications of this procedure to advanced cases and those with rectal cancer, however, it will be necessary to evaluate this technique's perioperative and long-term oncological safety in a large, randomized controlled trial.

\section{Abbreviations}

ASA: American Society of Anesthesiologists; BMI: Body mass index; C-LAC: Conventional laparoscopic colectomy; NOTES: Natural orifice transluminal endoscopic surgery; S-LAC: Single-port laparoscopic colectomy.

\section{Author details}

${ }^{1}$ Department of Surgery, Division of Frontier Medical Science, Programs for Biomedical Research, Graduate School of Biomedical Sciences, Hiroshima University, 1-2-3 Kasumi, Minami-ku, Hiroshima 734-8551, Japan. ${ }^{2}$ Advanced Medical Skills Training Center, Graduate School of Biomedical Sciences, Hiroshima University, 1-2-3 Kasumi, Minami-ku, Hiroshima 734-8551, Hiroshima, Japan. ${ }^{3}$ Department of Surgery, Hiroshima Prefectural Hospital, 15-54 Ujina-Kanda, Minami-ku, Hiroshima 734-8530, Japan.

\section{Authors' contributions}

$\mathrm{HE}$ participated in the treatment of these patients and the literature search and drafted the manuscript. MH helped to draft the manuscript. TH, YT, YK, MS, MT, TA, TU and TI participated in the treatment of these patients. $\mathrm{HO}$ participated in treatment planning for these patients and helped to draft the manuscript. All authors read and approved the final manuscript.

\section{Competing interests}

The authors declare that they have no competing interests.

Received: 27 February 2012 Accepted: 24 April 2012

Published: 24 April 2012

\section{References}

1. Jacobs M, Verdeja JC, Goldstein HS: Minimally invasive colon resection (laparoscopic colectomy). Surg Laparosc Endosc 1991, 1:144-150.

2. Lacy AM, García-Valdecasas JC, Delgado S, Castells A, Taurá P, Piqué JM, Visa J: Laparoscopy-assisted colectomy versus open colectomy for treatment of non-metastatic colon cancer: a randomised trial. Lancet 2002, 359:2224-2229.

3. Clinical Outcomes of Surgical Therapy Study Group: A comparison of laparoscopically assisted and open colectomy for colon cancer. $N$ Engl J Med 2004, 350:2050-2059.

4. Kalloo AN, Singh VK, Jagannath SB, Niiyama H, Hill SL, Vaughn CA, Magee CA, Kantsevoy SV: Flexible transgastric peritoneoscopy: a novel approach to diagnostic and therapeutic interventions in the peritoneal cavity. Gastrointest Endosc 2004, 60:114-117.

5. Marescaux J, Dallemagne B, Perretta S, Wattiez A, Mutter D, Coumaros D: Surgery without scars: report of transluminal cholecystectomy in a human being. Arch Surg 2007, 142:823-827.

6. Brunner W, Schirnhofer J, Waldstein-Wartenberg N, Frass R, Weiss H: Single incision laparoscopic sigmoid colon resections without visible scar: a novel technique. Colorectal Dis 2010, 12:66-70.

7. Bucher P, Pugin F, Morel P: Single-port access laparoscopic right hemicolectomy. Int J Colorectal Dis 2008, 23:1013-1016.

8. Choi SI, Lee KY, Park SJ, Lee SH: Single port laparoscopic right hemicolectomy with D3 dissection for advanced colon cancer. World J Surg 2010, 16:275-278.

9. Law WL, Fan JK, Poon JT: Single-incision laparoscopic colectomy: early experience. Dis Colon Rectum 2010, 53:284-288.

10. Leroy J, Cahill RA, Asakuma M, Dallemagne B, Marescaux J: Single-access laparoscopic sigmoidectomy as definitive surgical management of prior diverticulitis in human patient. Arch Surg 2009, 144:173-179.

11. Merchant AM, Lin E: Single-incision laparoscopic right hemicolectomy for a colon mass. Dis Colon Rectum 2009, 52:1021-1024.

12. Ramos-Valadez DI, Patel CB, Ragupathi M, Bartley Pickron T, Haas EM: Single-incision laparoscopic right hemicolectomy: safety and feasibility in a series of consecutive cases. Surg Endosc 2010, 24:2613-2616.

13. Remzi FH, Kirat HT, Kaouk JH, Geisler DP: Single-port laparoscopy in colorectal surgery. Colorectal Dis 2008, 10:823-826.

14. Rieger NA, Lam FF: Single-incision laparoscopically assisted colectomy using standard laparoscopic instrumentation. Surg Endosc 2010, 24:888-890.

15. Piskun G, Rajpal S: Transumbilical laparoscopic cholecystectomy utilizes no incisions outside the umbilicus. J Laparoendosc Adv Surg Tech A 1999, 9:361-364. 
16. Egi H, Okajima M, Hinoi T, Takakura Y, Kawaguchi $Y$, Shimomura $M$, Tokunaga M, Adachi T, Hattori M, Urushihara T, Itamoto T, Ohdan H: Singleincision laparoscopic colectomy using the Gelport system for early colon cancer. Scand J Surg 2012, 101:16-20.

doi:10.1186/1477-7819-10-61

Cite this article as: Egi et al:: Single-port laparoscopic colectomy versus conventional laparoscopic colectomy for colon cancer: a comparison of surgical results. World Journal of Surgical Oncology 2012 10:61.

Submit your next manuscript to BioMed Central and take full advantage of:

- Convenient online submission

- Thorough peer review

- No space constraints or color figure charges

- Immediate publication on acceptance

- Inclusion in PubMed, CAS, Scopus and Google Scholar

- Research which is freely available for redistribution

Submit your manuscript at www.biomedcentral.com/submit
() Biomed Central 